\title{
PENSION SERVICE INSTITUTION SELECTION BY A PERSONALIZED QUANTIFIER-BASED MACONT METHOD
}

\author{
Zhi WEN (D), Huchang LIAO (D) * \\ Business School, Sichuan University, 610064 Chengdu, China
}

Received 24 February 2021; accepted 15 September 2021

\begin{abstract}
With the emergence of a variety of pension service institutions, how to choose a suitable institution has become a strategic decision-making problem faced by pension service demanders. To solve this problem, this study identifies key evaluation criteria of pension service institutions through the analysis of the relevant literature. Then, this study proposes a mixed aggregation by comprehensive normalization technique (MACONT) with a personalized quantifier to select pension service institutions, where the personalized qualifier with cubic spline interpolation is used to derive the position weights of criteria, and the MACONT is improved to determine the ranking of alternatives. A case study about the selection of pension service institutions is provided to verify the feasibility of the proposed model. It is found that the proposed method is effective in dealing with heterogeneous evaluation information, and the personalized quantifiers can be combined with MACONT methods to obtain an optimal solution associated with the attitude of pension service demanders. The identified key evaluation criteria are not only significant for pension service demanders, but also conducive to the further improvement of property management related to pension services.
\end{abstract}

Keywords: multi-criteria decision making, pension service evaluation, personalized quantifier, cubic spline interpolation, MACONT method, probabilistic linguistic term set.

\section{Introduction}

As reported by the World Health Organization, the proportion of the world's population over the age of 60 is expected to increase from $12 \%$ to $22 \%$ in $2015-2050^{1}$. With the rapid growth of the global aging population, the demand for pension services has become increasingly prominent (Shao et al., 2021). This phenomenon is obvious in China, which has the largest aging population in the world. To meet the urgent needs for pension services, the number and scale of pension service institutions have increased significantly (Yuan et al., 2019). However, there is a big gap in the construction level of pension service institutions. To adapt to the trend of China's aging population, implement the strategy of actively responding to the aging population, and improve the living conditions of the elderly, China has put forward relevant regulations on the location and layout of residential buildings for the elderly, road traffic, site facilities, green landscape, public space, inner space, etc ${ }^{2}$. The

\footnotetext{
1 https://www.who.int/ageing/publications/world-report-2015/en/

2 http://www.yanglaocn.com/shtml/20171020/1508511349112939. html
}

introduction of this national standard promotes the overall improvement of the construction level of pension service institutions. In this scenario, how to choose an appropriate pension service institution becomes a strategic decisionmaking problem faced by pension service demanders. They need to make a trade-off towards the cost, environment, facilities, service quality and operation management efficiency of different pension service institutions. This study is devoted to introducing a multi-criteria decision-making (MCDM) model to evaluate pension service institutions and select the most suitable one.

The above MCDM problem involves the evaluations of multiple institutions under various criteria. At present, the research on the evaluation criteria of pension service institutions has been developed (Wang, 2020; Shao et al., 2020, 2021), but these studies involve a large number of evaluation criteria, which may be complex for pension service demanders. In this term, this study identifies key evaluation criteria of pension service institutions through the analysis of the relevant literature. On the one hand, the determination of the evaluation criteria can provide reference for pension service demanders in selecting the

${ }^{*}$ Corresponding author. E-mail: liaohuchang@163.com

Copyright $\odot 2021$ The Author(s). Published by Vilnius Gediminas Technical University

This is an Open Access article distributed under the terms of the Creative Commons Attribution License (https://creativecommons.org/licenses/by/4.0/), which permits unrestricted use, distribution, and reproduction in any medium, provided the original author and source are credited. 
appropriate service institutions; On the other hand, it provides reference for real estate enterprises to consider the factors in the process of investment and construction of pension service institutions. Moreover, with the rising of the combination mode of property and pension, with the key evaluation criteria of pension service institutions as reference, property enterprises can improve the corresponding quality of pension service to enhance their property management level.

Considering that the evaluation criteria may be qualitative or quantitative, we need to use different evaluation information expression tools. For quantitative criteria, crisp values can be used as an expression tool to reflect the objective performance of candidates since those values can be measured easily. For qualitative criteria, linguistic terms can be employed to express a decision-maker's subjective and complex cognition towards the performance of alternatives. Specifically, the probabilistic linguistic term set (PLTS) (Pang et al., 2016) has been regarded as a flexible and effective tool to express complex cognitive information (Liao et al., 2020; Mi et al., 2020). Hence, this study adopts crisp values and PLTSs to respectively express the evaluation information of quantitative and qualitative criteria. In addition, when processing the evaluation information, the crisp values and PLTSs cannot be transformed to each other, but are processed according to the distances between the performance of candidates under each criterion. We propose a novel distance measure to identify the distances between PLTSs.

When choosing pension service institutions, different pension service demanders may hold different attitudes. Specifically, some demanders may have a positive attitude, that is, they have a high level of requirement for the performance of institutions under each criterion, while some demanders may have a neutral attitude, that is, the performance of institutions under each criterion only needs to meet the general level. Different attitudes of demanders may lead to different decision-making results, and only the results associated with the attitudes of demanders fit the reality. Inspired by this idea, we use the personalized quantifier with cubic spline interpolation (Wen et al., 2021) to depict the attitude characteristics of demanders and derive the position weights of criteria (regarding the introduction of personalized quantifiers, please refer to Section 1.2).

The position weights of criteria are often applied in the ordered weighted aggregation (OWA) (Yager, 1988) operator to get the ranking of alternatives. However, the OWA operator only considers the compensation effect among criteria but ignores the non-compensation effect among criteria. The mixed aggregation by comprehensive normalization technique (MACONT) (Wen et al., 2020) is an MCDM method based on two aggregation operators regarding the distances between alternatives. The combination of the two aggregation operators takes into account the compensation and non-compensation effects between criteria simultaneously. However, one of the aggregation operators used in the MACONT method is defective. In this regard, this study proposes an improved MACONT method, and combines this method with the personalized quantifier to develop an enhanced MCDM model for pension service institution selection.

To sum up, this study is devoted to achieving the following innovative work:

a. We identify key criteria for pension service institution evaluation through the analysis of the relevant literature, which provides reference for pension service demanders in selecting pension service institutions.

b. We adopt crisp values and PLTSs to respectively express the evaluation information of quantitative and qualitative criteria, which is more convenient for practical application than using a single form of information expression. A novel distance measure of PLTSs is proposed to facilitate further analysis.

c. We improve the MACONT method and integrate the personalized quantifier with cubic spline interpolation with the improved MACONT method. The personalized quantifier is used to derive the position weights of criteria, while the enhanced MACONT method is used to determine the ranking of alternatives.

d. We propose the procedure of the personalized quantifier-based MACONT method and use it to solve the decision-making problem of selecting pension service institutions. The case study provides strategic decision-making insights for pension service demanders.

The structure of this study is organized as follows: Section 1 briefly reviews the PLTS, personalized quantifier with cubic spline interpolation, MACONT method and evaluation criteria of pension services. Section 2 introduces a distance measurement approach between PLTSs, and proposes the procedure of the personalized quantifier-based MACONT method. Section 3 gives a case study to illustrate the applicability of the proposed method in the evaluation and selection of pension service institutions. Section 4 makes sensitivity analysis and comparative analysis to emphasize the advantages of the proposed method. The last section summarizes the work of this study, explains the research limitations and explores future research directions.

\section{Preliminaries}

This section reviews the concept of PLTS and distance measures between PLTSs. The personalized quantifier with cubic spline interpolation and the MACONT method is then introduced. Finally, we provide a literature review on the evaluation criteria of pension service institutions.

\subsection{Pension service and its evaluation criteria}

Pension service refers to providing necessary life services for the elderly to meet their basic needs of material life 
and spiritual life ${ }^{3}$. Compared with the general service, the pension service has the following characteristics: 1) the service objects are vulnerable groups, and the ability of these groups towards service selection, influence and expression is weak; 2) the pension service has value orientation. Social service includes group value, social compensation, citizenship and others, while the pension service is not only to meet the public needs, but also to solve social problems, and thus is related to the dignity, fairness and trust of service objects; 3 ) the pension service is a public welfare, that is to say, for the elderly, the service should be very convenient and free or cheap (Wang, 2020). Therefore, the performance evaluation of pension service is different from that of general services.

In the research of performance evaluation of pension service, various evaluation criteria have been proposed. Kane and Kane (1988) proposed that the service quality of pension service institutions can be evaluated by six indicators, including cognitive ability, health impact, social activities, self-care ability, physical function and satisfaction. Zhao and Fang (2016) established a service quality evaluation model of pension institutions from five dimensions, including spiritual comfort service, medical care service, help urgent service, cleaning service and help meal service. Xu and Zhou (2019) measured the service quality of community home endowment service based on five evaluation dimensions in terms of infrastructure, living environment, daily life services, medical care services and spiritual comfort services. Ji et al. (2020) constructed a performance evaluation system of pension service, which includes seven dimensions such as system specification, purchase investment, carrying capacity, fairness, service quality, degree of satisfaction and influence. Wang (2020) constructed a quality evaluation system of home endowment service from four dimensions of service content quality (life care, spiritual care, cultural entertainment, social integration), service process quality (hardware technology level, software specialization level, service personnel internal input level), service result quality (satisfaction with various service contents) and service influence quality (sustainability, human nature and public welfare). Liang and Wang (2020) evaluated the performance of community home endowment service institutions from four aspects: fund management (the source of funds, the use of funds, and the supervision of funds), organization management (file management, organization system management, service personnel management, health and safety management), service object (service content, service facilities, service results, service efficiency), construction of service personnel (stability, professionalism, quality and attitude of service team). Shao et al. (2020) evaluated the performance of social organizations participating in community home endowment services from six aspects:

\footnotetext{
3 https://baike.baidu.com/item/\%E5\%85\%BB\%E8\%80\%81\%E6 \%9C\%8D\%E5\%8A\%A1/5079287?fr=aladdin
}

financial management (financial funds, donation funds, other income and operating income), hardware facilities (house nature, site area, number of beds, fixed assets), service quality (service type, service quantity, customer satisfaction and complaint quantity), team building (the number of management personnel, service personnel, social workers, volunteers and staff quality), organization construction (financial system construction, post system construction, security system construction, reward and punishment system construction, service process construction, emergency disposal process construction, complaint handling mechanism, opinion and suggestion handling mechanism). Juan et al. (2021) selected the most suitable campus for the transformation into a daily care center for the aged based on the key factors of convenient transportation, medical opportunities, barrier free space and ventilation. Based on literature analysis and expert interviews, Shao et al. (2021) constructed a performance evaluation system framework for pension service institutions, which is composed of 33 indicators from six dimensions of financial management (government funding, donated funding, other funding, overall financial evaluation, operating income), hardware facilities (total amount of fixed assets, number of beds, size of site, land use), team development (employee satisfaction level, training management level, qualification management evaluation, number of other service personnel, number of volunteers, number of social workers, number of staff, number of administrative staff), service management (quality of other services, quality of basic services, types of other services, types of basic services), organization management (degree of comments and suggestions handing perfection, degree of complaint handing perfection, degree of emergency management perfection, degree of service process perfection, degree of reward and punishment system perfection, degree of security system perfection, reasonable degree of organizational structure, degree of financial regulations perfection), and elderly care recipients (number of complaints, elderly satisfaction, coverage of social services for the elderly, number of old people served). According to the evaluation criteria in above-mentioned literature, this paper will extract the key factors as the evaluation criteria of pension service institutions.

\subsection{The MACONT method}

The MACONT method (Wen et al., 2020), as a recentlyproposed MCDM method, integrates three linear normalization techniques and two mixed aggregation operators to obtain a comprehensive solution. The three normalization techniques are linear sum-based normalization, linear ratio-based normalization, and linear max-min normalization. The three types of normalized performance values of each alternative over each criterion are combined by introducing a parameter to obtain a comprehensive normalized value. The two mixed aggregation operators are respectively inspired by the WASPAS method (Zavadskas 
et al., 2012) and MULTIMOORA method (Brauers \& Zavadskas, 2010). One aggregation operator is a mixture of the arithmetic weighted aggregation operator and geometric weighted aggregation operator, and the other is a mixture of the best performance and the worst performance of alternatives under all criteria.

For an MCDM decision-making problem, the procedure of the MACONT method is described as follows:

Step 1. Construct a decision matrix according to the evaluation information of alternatives under different criteria.

Step 2. Normalize the decision matrix by three linear normalization techniques, and derive a comprehensive normalized decision matrix.

Step 3. Set the average performance of alternatives under all criteria as a reference alternative, and calculate the distance between each alternative and the reference alternative.

Step 4. Aggregate the distance values of alternatives by two mixed aggregation operators, and deduce the final comprehensive scores to rank alternatives and determine the optimal one. End.

The MACONT method is helpful to reduce the deviation caused by single normalization technique. After establishing the reference alternative, the MACONT method can comprehensively consider the good performance and bad performance of an alternative. In terms of aggregation operators, the MACONT method takes into account the compensability and non-compensability among criteria. The parameters designed in the MACONT method can enhance the flexibility of solving practical decision-making problems. Although this method has these advantages, its applicability in fuzzy and uncertain decision-making environments remains to be investigated.

\subsection{Personalized quantifiers}

In general, decision-makers are inevitably influenced by their personal attitudes when making decisions. Different decision attitudes may produce different decision-making results. To capture a decision-maker's attitude, Guo (2014) put forward the personalized quantifier based on the idea of the OWA operator, and adopted different interpolation functions to generate individual quantifiers. Guo (2014) first used the piecewise linear interpolation function to generate individual quantifiers, but the fitting function image is rigid (Guo, 2014). Then, Guo (2016) used the Bernstein polynomials to depict personalized quantifiers, but the accuracy of the fitting function at the connection point decreased. Subsequently, Guo and Xu (2018) integrated the Bernstein polynomials with the interpolation spline to produce personalized quantifiers, but the image of the fitting function fluctuated greatly. To further bridge these gaps, Wen et al. (2021) proposed the personalized quantifier with cubic spline interpolation. The personalized quantifier fitted by the cubic spline interpolation has both the acceptable accuracy of the function value at the connection point and the smoothness of the function image. It can be described as follows:
Let $G_{i j}$ denote the distance between the evaluation information of the $i$-th alternative on the $j$-th criterion and the subjective expectation value of the $j$-th criterion provided by a decision-maker. The attitudinal weight of each alternative can be derived by $\eta_{i}=1 /\left[\left(\sum_{j=1}^{n} G_{i j}{ }^{2}\right)\left(\sum_{i=1}^{m} 1 /\left(\sum_{j=1}^{n} G_{i j}{ }^{2}\right)\right)\right]$. The personalized quantifier with cubic spline interpolation, $Q(x)$, can be represented as:

$$
\begin{aligned}
Q(x) & =m\left[\frac{\gamma_{i-1}}{6}\left(\frac{i}{m}-x\right)^{3}+\frac{\gamma_{i}}{6}\left(x-\frac{i-1}{m}\right)^{3}+\right. \\
\left.\left(\sum_{k=1}^{i-1} \eta_{k}-\frac{\gamma_{i-1}}{6 m^{2}}\right)\left(\frac{i}{m}-x\right)+\left(\sum_{k=1}^{i} \eta_{k}-\frac{\gamma_{i}}{6 m^{2}}\right)\left(x-\frac{i-1}{m}\right)\right] & \\
x & \in\left[\frac{i-1}{m}, \frac{i}{m}\right]
\end{aligned}
$$

where the coefficients $\gamma_{i}(i=1,2, \cdots, m)$ are calculated by $0.5 \gamma_{i-1}+2 \gamma_{i}+0.5 \gamma_{i+1}=3 m^{2}\left(\eta_{i+1}-\eta_{i}\right)$, and $\gamma_{0}=\gamma_{m}=0$.

The personalized quantifiers can be used to derive the position weights of criteria in the OWA operator, shown as:

$$
w_{j}=Q(j / n)-Q((j-1) / n), \text { for } j=1,2, \cdots, n .
$$

\subsection{Probabilistic linguistic term set}

The linguistic term set consisting of ordered and finite linguistic terms is an effective tool to express the complex and uncertain perceptions of decision-makers on candidate objects in a decision-making problem. Let a linguistic term set be $S=\left\{s_{\alpha} \mid \alpha=0,1 \cdots, 2 \tau\right\}$ where $\tau$ is a positive integer. Separate linguistic terms are usually not enough to reflect the hesitancy of decision-makers among several linguistic terms. In this sense, the HFLTS (hesitant fuzzy linguistic term set, Rodríguez et al., 2012) was proposed to enable decision-makers to measure the performance of an object under each criterion in several linguistic terms. Liao et al. (2015) put forward the mathematical expression of HFLTSs, in which the linguistic terms are considered to be continuous and each linguistic term has the same weight in a hesitant fuzzy linguistic element. To emphasize that the linguistic terms may have different relative importance in the consciousness of decision-makers, Pang et al. (2016) further introduced the PLTS which can be mathematically expressed as $L(p)=\left\{s_{\alpha}^{(t)}\left(p^{(t)}\right) \mid s_{\alpha}^{(t)} \in S ; p^{(t)} \geq 0 ; t=1,2, \cdots, T ; \sum_{t=1}^{T} p^{(t)} \leq 1\right\}$, where $T$ denotes the number of linguistic terms in $L(p)$, and $s_{\alpha}^{(t)}\left(p^{(t)}\right)$ denotes the $t$-th linguistic term $s_{\alpha}^{(t)}$ associated with the probability $p^{(t)}$.

The comparison of PLTSs can be made by Eq. (3), where $\alpha^{(t)}$ is the subscript of $s_{\alpha}^{(t)}$ and $p^{*(t)}$ is the probability related to $s_{\alpha}^{(t)}$ and normalized by $p^{(t)} / \sum_{t=1}^{T} p^{(t)}$. Lin et al. (2020) introduced the distance measure between PLTSs $L_{1}(p)$ and $L_{2}(p)$ based on the classical Euclidean distance measure, as shown in Eq. (4), where $p_{1}^{*(t)}-p_{2}^{*(t)}$ denotes the difference of the normalized probabilities of the same linguistic terms in $L_{1}(p)$ and $L_{2}(p)$. 


$$
\begin{aligned}
& \sum_{t=1}^{T} \alpha^{(t)} p^{*(t)} ; \\
& D\left(L_{1}(p), L_{2}(p)\right)=\sqrt{\sum_{t=1}^{T}\left[\frac{\alpha^{(t)}}{2 \tau}\left(p_{1}^{*}(t)-p_{2}^{*(t)}\right)\right]^{2}} .
\end{aligned}
$$

\section{A personalized quantifier-based MACONT method for multi-criteria decision making}

In this section, we propose an MCDM method based on the combination of the PLTS, personalized quantifier with cubic spline interpolation and the enhanced MACONT method. Section 2.1 introduces a distance measure of PLTSs. Section 2.2 describes the procedure of the proposed MCDM method in detail.

\subsection{Distance measure between probabilistic linguistic term sets}

Various distance measures have been proposed to measure the distance between PLTSs (Zhang et al., 2016; Bai et al., 2017; Wu \& Liao, 2018; Lin et al., 2019). These measures can be divided into two categories, depending on whether to add linguistic terms to the given PLTSs or not. For the first kind of measures which add linguistic terms to PLTSs, there are two questions: which linguistic terms should be selected to supplement a PLTSs; how to assign the probability of the added linguistic terms. Different schemes to these two questions may result in different distance values between PLTSs. To avoid these issues, we focus on the other kind of distance measures which do not require to add linguistic terms to PLTSs. Eq. (4) is one of the second kind of methods.

However, when we use Eq. (4) to measure the distance between PLTSs, there may be some limitations. For three normalized PLTSs $L_{1}^{*}(p)=\left\{s_{5}(1)\right\}, L_{2}^{*}(p)=\left\{s_{5}(0.444), s_{6}(0.556)\right\}$ and $L_{3}^{*}(p)=\left\{s_{3}(0.139), s_{4}(0.267), s_{5}(0.455), s_{6}(0.139)\right\}$. By Eq. (3), we have $L_{3}^{*}(p)<L_{1}^{*}(p)<L_{2}^{*}(p)$, from which we can deduce $D\left(L_{1}^{*}(p), L_{3}^{*}(p)\right)<D\left(L_{2}^{*}(p), L_{3}^{*}(p)\right)$. Nevertheless, by Eq. (4), $D\left(L_{1}^{*}(p), L_{3}^{*}(p)\right)=0.512, D\left(L_{2}^{*}(p), L_{3}^{*}(p)\right)=0.459$. It follows $D\left(L_{1}^{*}(p), L_{3}^{*}(p)\right)>D\left(L_{2}^{*}(p), L_{3}^{*}(p)\right)$, which is not reasonable.

Inspired by the expectation value function of PLTSs (Wu \& Liao, 2019), we propose a distance measure between PLTSs as:

$$
\begin{aligned}
& D\left(L^{1}(p), L^{2}(p)\right)= \\
& \sqrt{\left.\mid \sum_{t=1}^{T} \frac{\alpha_{1}^{(t)}}{2 \tau} p_{1}^{*(t)}\right)^{2}-\left(\sum_{t=1}^{T} \frac{\alpha_{2}^{(t)}}{2 \tau} p_{2}^{*(t)}\right)^{2} \mid} .
\end{aligned}
$$

By Eq. (5), the distance between the PLTSs in the above example can be measured as $D\left(L_{1}^{*}(p), L_{3}^{*}(p)\right)=0.329$ $D\left(L_{2}^{*}(p), L_{3}^{*}(p)\right)=0.521$. Thus, $D\left(L_{1}^{*}(p), L_{3}^{*}(p)\right)<D\left(L_{2}^{*}(p)\right.$, $\left.L_{3}^{*}(p)\right)$. Compared with the distance measure given in Eq. $(4)$, Eq. (5) is more reasonable.

\subsection{An MCDM model based on the personalized quantifier and MACONT method}

For an MCDM problem with $m$ alternatives and $n$ criteria, the evaluation information of alternatives over criteria usually has two forms: qualitative and quantitative. Assuming that the qualitative information is represented by PLTSs and the quantitative information is represented by crisp values, a decision matrix containing qualitative and quantitative evaluation information provided by a decision-maker can be established as:

$$
\left[\begin{array}{cccccc}
L_{11}(p) & v_{12} & \cdots & L_{1 j}(p) & \cdots & v_{1 n} \\
L_{21}(p) & v_{22} & \cdots & L_{2 j}(p) & \cdots & v_{2 n} \\
\vdots & \vdots & \ddots & \vdots & \ddots & \vdots \\
L_{i 1}(p) & v_{i 2} & \cdots & L_{i j}(p) & \cdots & v_{i n} \\
\vdots & \vdots & \ddots & \vdots & \ddots & \vdots \\
L_{m 1}(p) & v_{m 2} & \cdots & L_{m j}(p) & \cdots & v_{m n}
\end{array}\right],
$$

where $L_{i j}(p)$ and $v_{i j}$ respectively represent the probabilistic linguistic or crisp evaluation information of the $i$-th alternative under the $j$-th criterion.

After the decision matrix is established, we can compare the performance of each alternative with the subjective expectation performance provided by the decisionmaker with respect to each criterion. The performance of each alternative under benefit criteria is arranged in descending order, while the performance of each alternative under cost criteria is arranged in ascending order. Measure the distance between the performance of each alternative and the subjective expectation performance under each criterion. The subjective expectation information under each criterion is supposed to be represented in the same form as those of the alternatives. The distances between PTLSs can be calculated by Eq. (5) and the distance between crisp values $v_{i j}^{1}$ and $v_{i j}^{2}$ are calculated by Eq. (6). These distance values are normalized by the linear sum-based normalization technique, as shown in Eq. (7).

$$
\begin{aligned}
& D\left(v_{i j}^{1}, v_{i j}^{2}\right)=\left|v_{i j}^{1}-v_{i j}^{2}\right| ; \\
& G_{i j}=\left\{\begin{array}{l}
D\left(L_{i j}(p), L_{j}(p)\right) / \sum_{i=1}^{m} D\left(L_{i j}(p), L_{j}(p)\right) \\
D\left(v_{i j}, v_{j}\right) / \sum_{i=1}^{m} D\left(v_{i j}, v_{j}\right)
\end{array}\right.
\end{aligned}
$$

where $L_{j}(p)$ and $v_{j}$ are subjective expectation values of the decision-maker in PLTS and crisp value, respectively.

The attitudinal weight of each alternative can be deduced and the personalized quantifier associated with the decisionmaker can be generated based on Eq. (3). Subsequently, based on the generated personalized quantifier and Eq. (4), the position weights of criteria can be derived, which are related to the decision attitude of the decision-maker.

Next, we determine the average performance of alternatives under each criterion. The average performance of PLTSs and crisp values can be determined by Eqs (8) and (9).

$$
\bar{L}_{i j}(p)=\left\{s_{\alpha}^{(t)}\left(\frac{\sum_{i=1}^{m} p_{i}^{*}(\alpha)}{\sum_{\alpha=0}^{2 \tau} \sum_{i=1}^{m} p_{i}^{*(\alpha)}}\right) \mid s_{\alpha}^{(t)} \in S ; p^{(t)} \geq 0 ; t=1,2, \cdots, T\right\} ;
$$

$$
\bar{v}_{i j}=\sum_{i=1}^{m} v_{i j} / n .
$$


Put these average performances together as a reference alternative, and compare the performance of each alternative under each criterion with that of the reference alternative. The performances of alternatives not less than that of the reference alternative is retained in the decision matrix (the performances of other alternatives are set to zero). Then, the distances between the performances of these alternatives and the reference alternative under each criterion are measured by Eqs (5) and (6), so as to obtain the positive distance matrix. In the same way, the distance between the performance of the reference alternative and those of the eliminated alternatives under each criterion are measured to obtain the negative distance matrix. Normalize the positive distance matrix and negative distance matrix by the linear sum-based normalization technique (i.e., Eq. (7)). The positive distance value $H_{i j}^{+}$of each alternative under all criterion in the positive distance matrix are ranked from large to small, while the negative distance value $H_{i j}^{-}$of each alternative under all criteria are ranked from small to large.

Combined with the position weights of criteria, two subordinate comprehensive scores of each alternative can be calculated by Eqs (10) and (11).

$$
\begin{gathered}
C S_{i}^{1}=\lambda \frac{\sum_{j=1}^{n} w_{j} H_{i j}^{+}-\sum_{j=1}^{n} w_{j} H_{i j}^{-}}{\sqrt{\sum_{i=1}^{m}\left(\sum_{j=1}^{n} w_{j} H_{i j}^{+}-\sum_{j=1}^{n} w_{j} H_{i j}^{-}\right)^{2}}}+ \\
(1-\lambda) \frac{\prod_{j=1}^{n}\left(1+H_{i j}^{+}\right)^{w_{j}} / \prod_{j=1}^{n}\left(1+H_{i j}^{-}\right)^{w_{j}}-1}{\sqrt{\sum_{i=1}^{m}\left(\prod_{j=1}^{n}\left(1+H_{i j}^{+}\right)^{w_{j}} / \prod_{j=1}^{n}\left(1+H_{i j}^{-}\right)^{w_{j}}-1\right)^{2}}} \\
C S_{i}^{2}=\mu \max _{j}\left(w_{j} H_{i j}^{+}\right)-(1-\mu) \max _{j}\left(w_{j} H_{i j}^{-}\right),
\end{gathered}
$$

$C S_{i}^{1}$ represents the combination of comprehensive performance and individual performance of alternatives, and the parameter $\lambda(\lambda \in[0,1])$ coordinates the proportion of the two performances in the mind of the decision-maker. In the original MACONT method (Wen et al., 2020), the individual performance of alternatives is calculated by $\prod_{j=1}^{n}\left(H_{i j}^{-}\right)^{w_{j}} / \prod_{j=1}^{n}\left(H_{i j}^{+}\right)^{w_{j}}$. This aggregation operator in the original MACONT method considers that the alternative with more positive distance or less negative distance has a higher score, but ignores the influence of distance values on alternative performances. Generally, the alternative with a larger positive distance value or a smaller negative distance value has a better performance, but the aggregation operator in the original MACONT method causes that the alternative with a larger positive distance or a smaller negative distance to perform better, which is unreasonable. Therefore, we improve this aggregation operator by $\prod_{j=1}^{n}\left(1+H_{i j}^{+}\right)^{w_{j}} / \prod_{j=1}^{n}\left(1+H_{i j}^{-}\right)^{w_{j}}-1$, which not only satisfies the property that the better performance of an alternative has more positive distance or less negative distance, but also satisfies the property that the better performance of an alternative has a large positive distance value or a small negative distance value.

$C S_{i}^{2}$ represents the combination of the best performance and the worst performance of each alternative, and $\mu(\mu \in[0,1])$ is a coordination parameter of the two performances. Eventually, we integrate $C S_{i}^{1}$ and $C S_{i}^{2}$ by Eq. (12) to obtain the final comprehensive score of each alternative. The alternatives are ranked in the descending order of these scores, and the alternative with the highest score is the optimal one.

$$
C S_{i}=\frac{1}{2} C S_{i}^{1}+\frac{1}{2}\left(C S_{i}^{2} / \sum_{i=1}^{m} C S_{i}^{2}\right) .
$$

The flow chart of the proposed personalized quantifierbased MACONT method is shown in Figure 1, and the algorithm is presented in Algorithm 1.

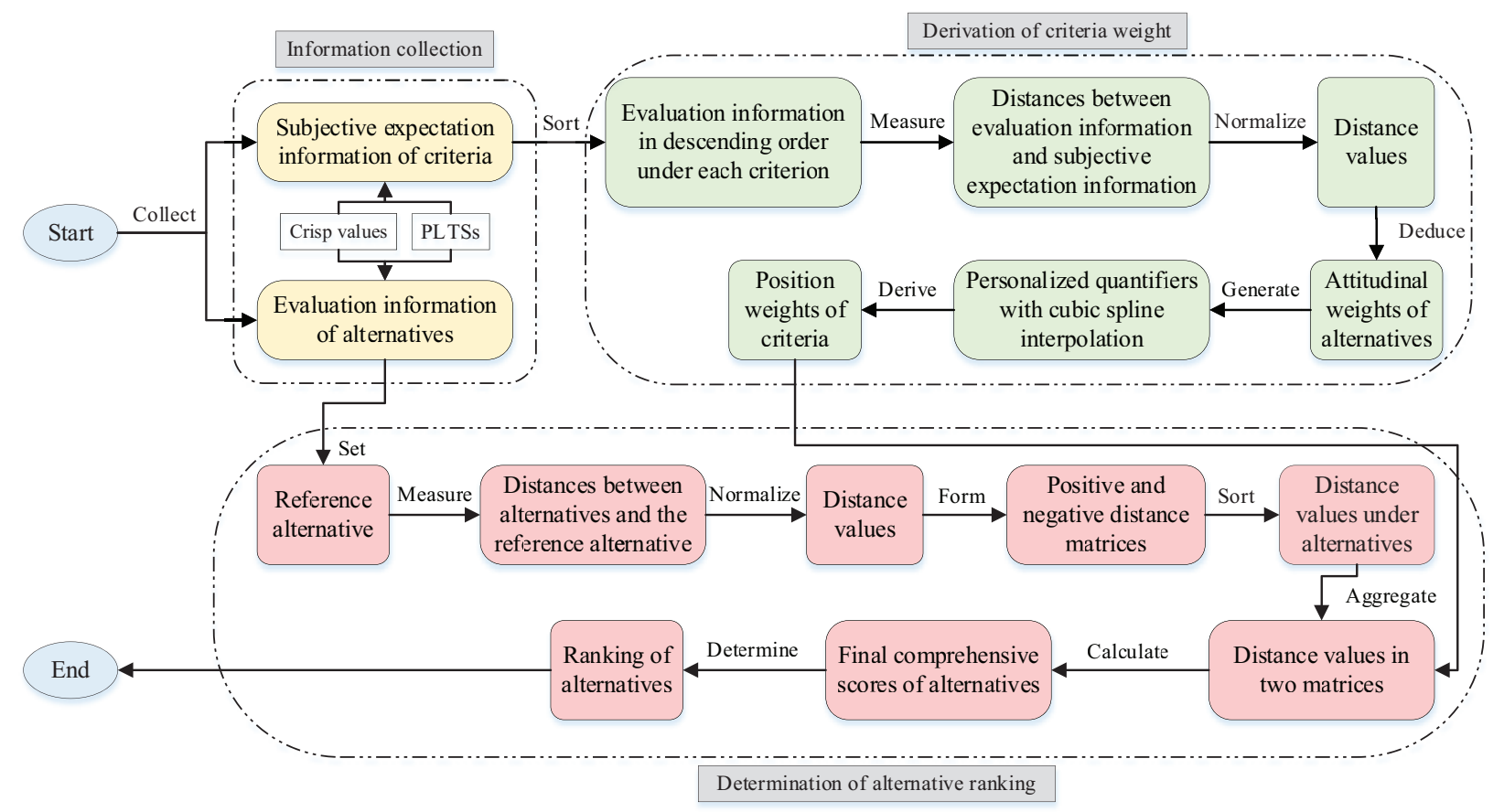

Figure 1. The flow chart of the personalized quantifier-based MACONT method 


\begin{abstract}
Algorithm 1. (The personalized quantifier-based MACONT method)
Input: The evaluation information of alternatives and subjective expectation information of criteria.

Output: The position weights of criteria and the ranking of alternatives.
\end{abstract}

Step 1. Arrange the performances of alternatives in descending order under each criterion, and measure the distances between the performance of alternatives under each criterion and the subjective expectation performance by Eqs (5) and (6).

Step 2. Calculate the attitudinal weights of alternatives and generate the personalized quantifiers with cubic spline interpolation based on Eq. (1).

Step 3. Derive the position weights of criteria based on Eq. (2).

Step 4. Set the average performance of each alternative as the reference alternative based on Eqs (8) and (9), and measure the distances between alternatives and the reference alternative.

Step 5. Combining with the position weights of criteria, we aggregate the distance values by Eqs (10) and (11), and obtain the final comprehensive score of each alternative by Eq. (12).

Step 6. Rank the alternatives according to the final comprehensive scores in descending order.

\section{Case study: evaluation and selection of pension service institutions}

According to the data released by China's National Bureau of Statistics, by the end of 2019, China had 254 million people aged 60 and above, accounting for $18.1 \%$ of the total population ${ }^{4}$. For Chengdu city (Sichuan, China), the number of elderly people aged 60 and above is 3.1604 million, accounting for $21.07 \%$ of the registered population, and the degree of aging is far higher than the national average ${ }^{5}$. From the above data, it is not difficult to see that Chengdu has a large number of pension demand, which means that there are a large number of pension service demanders in Chengdu facing the choice of pension service institutions.

Suppose that there is a pension service demander in Chengdu who wants to choose a pension service institution. From the 84 existing pension service institutions in Cheng$\mathrm{du}$, he/she selected 6 pension service institutions, $P I_{1}, P I_{2}$, $\mathrm{PI}_{3}, \mathrm{PI}_{4}, \mathrm{PI}_{5}, \mathrm{PI}_{6}$, with relatively good reputation as candidates. There are three rules for these alternative institutions to be selected: a. their relevant information is easy to obtain on the network; $b$. the minimum cost that the demander needs to pay is relatively low; c. the living environment is relatively good. Among these pension service institutions, $P I_{1}, P I_{4}$ and $P I_{5}$ are located in suburban areas with beautiful environment; $P I_{2}, P I_{3}$ and $P I_{6}$ are located in the main urban area with convenient transportation. According to the analysis of the relevant literature in Section 2.1, 14 criteria are identified from the five dimensions of cost, environment, facilities and equipment, service and operation management to evaluate these six institutions, which are listed in Table 1. Among these criteria, $C_{1}, C_{2}, C_{3}$ and $C_{4}$ are quantitative criteria; $C_{5}, C_{6}, C_{7}, C_{8}, C_{9}, C_{10}, C_{11}$, $C_{12}, C_{13}$ and $C_{14}$ are qualitative criteria. Except that $C_{1}$ and $C_{2}$ are cost criteria, the other 12 criteria are benefit criteria. Based on the linguistic term set $\left\{s_{0}:\right.$ very good, $s_{1}$ : good, $s_{2}$ : slightly good, $s_{3}:$ medium, $s_{4}$ : slightly poor, $s_{5}:$ poor, $s_{6}:$ very poor $\}$, the subjective expectation information of alternatives under each criterion given by the pension service demander is:

[3000 $7000800050 \%\left\{s_{5}(0.5), s_{6}(0.5)\right\}\left\{s_{5}(0.4), s_{6}(0.6)\right\}$ $\left\{s_{5}(0.8), s_{6}(0.2)\right\}\left\{s_{4}(0.3), s_{5}(0.5)\right\}\left\{s_{6}(0.8)\right\}\left\{s_{3}(0.3), s_{4}(0.7)\right\}$ $\left.\left\{s_{4}(0.9), s_{5}(0.1)\right\}\left\{s_{4}(0.7), s_{5}(0.3)\right\}\left\{s_{5}(0.4), s_{6}(0.4)\right\}\left\{s_{5}(1)\right\}\right]$.

According to the evaluation information of these six pension service institutions under fourteen criteria provided by the demander, the decision matrix is formed as:

$\left[\begin{array}{llllll}4000 & 4000 & 3000 & 4000 & 4000 & 3000 \\ 12000 & 6000 & 6000 & 8000 & 10000 & 8000 \\ 2030 & 12000 & 16000 & 4200 & 8500 & 6500 \\ 40 \% & 70 \% & 30 \% & 10 \% & 35 \% \\ \left\{s_{5}(0.8)\right\} & \left\{s_{5}(0.5), s_{6}(0.5)\right\} & \left\{s_{3}(0.3), s_{4}(0.6)\right\} & \left\{s_{6}(0.7)\right\} & \left\{s_{6}(0.8)\right\} & \left\{s_{4}(0.5), s_{5}(0.3)\right\} \\ \left\{s_{4}(0.3), s_{5}(0.6)\right\} & \left\{s_{6}(1)\right\} & \left\{s_{4}(0.5), s_{5}(0.5)\right\} & \left\{s_{1}(0.2), s_{2}(0.4), s_{3}(0.2)\right\} & \left\{s_{2}(0.3), s_{3}(0.6)\right\} & \left\{s_{3}(0.3), s_{4}(0.7)\right\} \\ \left\{s_{2}(0.4), s_{3}(0.5)\right\} & \left\{s_{5}(0.8)\right\} & \left\{s_{5}(0.7), s_{6}(0.3)\right\} & \left\{s_{3}(1)\right\} & \left\{s_{4}(0.2), s_{5}(0.8)\right\} & \left\{s_{3}(0.5), s_{4}(0.4)\right\} \\ \left\{s_{3}(1)\right\} & \left\{s_{3}(0.6), s_{4}(0.2)\right\} & \left\{s_{5}(0.9)\right\} & \left\{s_{3}(0.5), s_{4}(0.3), s_{5}(0.2)\right\} & \left\{s_{6}(1)\right\} & \left\{s_{2}(0.4), s_{3}(0.5)\right\} \\ \left\{s_{6}(0.8)\right\} & \left\{s_{1}(0.3), s_{2}(0.3), s_{3}(0.4)\right\} & \left\{s_{5}(0.5), s_{6}(0.3)\right\} & \left\{s_{3}(0.2), s_{4}(0.6)\right\} & \left\{s_{5}(0.7), s_{6}(0.3)\right\}\left\{s_{4}(0.2), s_{5}(0.8)\right\} \\ \left\{s_{4}(0.3), s_{5}(0.5)\right\} & \left\{s_{3}(1)\right\} & \left\{s_{4}(0.2), s_{5}(0.8)\right\} & \left\{s_{4}(0.7)\right\} & \left\{s_{5}(0.4), s_{6}(0.4)\right\}\left\{s_{3}(0.6), s_{4}(0.2)\right\} \\ \left\{s_{5}(0.5), s_{6}(0.5)\right\} & \left\{s_{3}(0.4), s_{4}(0.4)\right\} & \left\{s_{4}(0.3), s_{5}(0.4), s_{6}(0.2)\right\} & \left\{s_{4}(0.2), s_{5}(0.8)\right\} & \left\{s_{3}(0.2), s_{4}(0.6)\right\}\left\{s_{3}(1)\right\} \\ \left\{s_{4}(0.2), s_{5}(0.7)\right\} & \left\{s_{5}(0.7)\right\} & \left\{s_{4}(0.7)\right\} & \left\{s_{4}(0.5), s_{5}(0.5)\right\} & \left\{s_{5}(1)\right\} & \left\{s_{5}(0.5), s_{6}(0.5)\right\} \\ \left\{s_{5}(0.3), s_{6}(0.5)\right\} & \left\{s_{4}(0.2), s_{5}(0.4)\right\} & \left\{s_{5}(0.5), s_{6}(0.3)\right\} & \left\{s_{3}(0.8)\right\} & \left\{s_{3}(0.6), s_{4}(0.2)\right\}\left\{s_{3}(0.9)\right\} \\ \left\{s_{6}(0.8)\right\} & \left\{s_{5}(0.3), s_{6}(0.5)\right\} & \left\{s_{4}(0.5), s_{5}(0.5)\right\} & \left\{s_{5}(0.3), s_{6}(0.7)\right\} & \left\{s_{4}(0.2), s_{5}(0.5)\right\}\left\{s_{4}(0.2), s_{5}(0.4), s_{6}(0.2)\right\}\end{array}\right]$

\footnotetext{
4 http://www.199it.com/archives/1068230.html

${ }^{5}$ http://www.360doc.com/content/20/1104/15/41569365_944071108. shtml
} 
Arrange each row of the decision matrix by comparing the performance of each institution under each criterion with the subjective expectation performance (the rows associated with the cost criterion are arranged in ascending order, while the rows associated with the benefit criterion are arranged in descending order). The arranged decision matrix is as follows:

\begin{tabular}{|c|c|c|c|c|c|}
\hline 3000 & 3000 & 4000 & 4000 & 4000 & 4000 \\
\hline 6000 & 6000 & 8000 & 8000 & 10000 & 12000 \\
\hline 16000 & 12000 & 8500 & 6500 & 4200 & 2030 \\
\hline $70 \%$ & $55 \%$ & $40 \%$ & $35 \%$ & $30 \%$ & $10 \%$ \\
\hline$\left\{s_{6}(0.8)\right\}$ & $\left\{s_{6}(0.7)\right\}$ & $\left\{s_{5}(0.5), s_{6}(0.5)\right\}$ & $\left\{s_{5}(0.8)\right\}$ & $\left\{s_{4}(0.5), s_{5}(0.3)\right\}$ & $\left\{s_{3}(0.3), s_{4}(0.6)\right\}$ \\
\hline$\left\{s_{6}(1)\right\}$ & $\left\{s_{4}(0.3), s_{5}(0.6)\right\}$ & $\left\{s_{4}(0.5), s_{5}(0.5)\right\}$ & $\left\{s_{3}(0.3), s_{4}(0.7)\right\}$ & $\left\{s_{2}(0.3), s_{3}(0.6)\right\}$ & $\left\{s_{1}(0.2), s_{2}(0.4), s_{3}(0.2)\right\}$ \\
\hline$\left\{s_{5}(0.7), s_{6}(0.3)\right\}$ & $\left\{s_{5}(0.8)\right\}$ & $\left\{s_{4}(0.2), s_{5}(0.8)\right\}$ & $\left\{s_{3}(0.5), s_{4}(0.4)\right\}$ & $\left\{s_{3}(1)\right\}$ & $\left\{s_{2}(0.4), s_{3}(0.5)\right\}$ \\
\hline$\left\{s_{6}(1)\right\}$ & $\left\{s_{5}(0.9)\right\}$ & $\left\{s_{3}(0.5), s_{4}(0.3), s_{5}(0.2)\right\}$ & $\left\{s_{3}(0.6), s_{4}(0.2)\right\}$ & $\left\{s_{3}(1)\right\}$ & $\left\{s_{2}(0.4), s_{3}(0.5)\right\}$ \\
\hline$\left\{s_{6}(0.8)\right\}$ & $\left\{s_{5}(0.5), s_{6}(0.3)\right\}$ & $\left\{s_{5}(0.7), s_{6}(0.3)\right\}$ & $\left\{s_{4}(0.2), s_{5}(0.8)\right\}$ & $\left\{s_{3}(0.2), s_{4}(0.6)\right\}$ & $\left\{s_{1}(0.3), s_{2}(0.3), s_{3}(0.4)\right\}$ \\
\hline$\left\{s_{5}(0.4), s_{6}(0.4)\right\}$ & $\left\{s_{4}(0.2), s_{5}(0.8)\right\}$ & $\left\{s_{4}(0.3), s_{5}(0.5)\right\}$ & $\left\{s_{4}(0.7)\right\}$ & $\left\{s_{3}(0.6), s_{4}(0.2)\right\}$ & $\left\{s_{3}(1)\right\}$ \\
\hline$\left\{s_{5}(0.5), s_{6}(0.5)\right\}$ & $\left\{s_{4}(0.3), s_{5}(0.4), s_{6}(0.2)\right\}$ & $\left\{s_{4}(0.2), s_{5}(0.8)\right\}$ & $\left\{s_{3}(0.2), s_{4}(0.6)\right\}$ & $\left\{s_{3}(0.4), s_{4}(0.4)\right\}$ & $\left\{s_{3}(1)\right\}$ \\
\hline$\left\{s_{5}(0.5), s_{6}(0.5)\right\}$ & $\left\{s_{5}(1)\right\}$ & $\left\{s_{5}(0.7)\right\}$ & $\left\{s_{4}(0.2), s_{5}(0.7)\right\}$ & $\left\{s_{4}(0.5), s_{5}(0.5)\right\}$ & $\left\{s_{4}(0.7)\right\}$ \\
\hline$\left\{s_{5}(0.3), s_{6}(0.5)\right\}$ & $\left\{s_{5}(0.5), s_{6}(0.3)\right\}$ & $\left\{s_{4}(0.2), s_{5}(0.4)\right\}$ & $\left\{s_{3}(0.6), s_{4}(0.2)\right\}$ & $\left\{s_{3}(0.9)\right\}$ & $\left\{s_{3}(0.8)\right\}$ \\
\hline$\left\{s_{6}(0.8)\right\}$ & $\left\{s_{5}(0.3), s_{6}(0.7)\right\}$ & $\left\{s_{5}(0.3), s_{6}(0.5)\right\}$ & $\left\{s_{4}(0.2), s_{5}(0.4), s_{6}(0.2)\right\}$ & $\left\{s_{4}(0.2), s_{5}(0.5)\right\}$ & $\left\{s_{4}(0.5), s_{5}(0.5)\right\}$ \\
\hline
\end{tabular}

Table 1. The evaluation criteria for pension service institutions

\begin{tabular}{|c|c|c|c|}
\hline Dimension & Evaluation criteria & Description & Source \\
\hline \multirow[t]{2}{*}{ Cost } & Minimum cost $\left(C_{1}\right)$ & $\begin{array}{l}\text { The minimum monthly fee for the elderly in the } \\
\text { pension service institution }\end{array}$ & - \\
\hline & Maximum cost $\left(C_{2}\right)$ & $\begin{array}{l}\text { The maximum monthly fee for the elderly in the } \\
\text { pension service institution }\end{array}$ & - \\
\hline \multirow[t]{4}{*}{ Environment } & Floorage $\left(C_{3}\right)$ & $\begin{array}{l}\text { The total horizontal area of each floor of various } \\
\text { buildings in the pension service institution }\end{array}$ & Wang, 2020; Shao et al., 2020, 2021 \\
\hline & $\begin{array}{l}\text { Green coverage rate } \\
\left(C_{4}\right)\end{array}$ & $\begin{array}{l}\text { The ratio of the green area to the floor area of the } \\
\text { pension service institution }\end{array}$ & $\mathrm{Xu}$ and Zhou, 2019 \\
\hline & $\begin{array}{l}\text { Room environment } \\
\left(C_{5}\right)\end{array}$ & $\begin{array}{l}\text { Including indoor layout, indoor lighting and } \\
\text { indoor noise }\end{array}$ & Xu and Zhou, 2019 \\
\hline & $\begin{array}{l}\text { Surrounding } \\
\text { environment }\left(C_{6}\right)\end{array}$ & $\begin{array}{l}\text { Including beautiful environment, convenient } \\
\text { transportation and public information graphic } \\
\text { identification }\end{array}$ & $\mathrm{Xu}$ and Zhou, 2019; Juan et al., 2021 \\
\hline \multirow[t]{3}{*}{$\begin{array}{l}\text { Facilities and } \\
\text { equipment }\end{array}$} & Living space $\left(C_{7}\right)$ & $\begin{array}{l}\text { Including residential space, activity space, and } \\
\text { parking area }\end{array}$ & $\begin{array}{l}\text { Kane and Kane, 1988; Shao et al., } \\
2020,2021\end{array}$ \\
\hline & Living facilities $\left(C_{8}\right)$ & $\begin{array}{l}\text { Diversity and completeness of indoor and outdoor } \\
\text { facilities }\end{array}$ & $\begin{array}{l}\text { Kane and Kane, 1988; Xu and Zhou, } \\
\text { 2019; Wang, 2020; Liang and Wang, } \\
\text { 2020; Shao et al., 2020, } 2021\end{array}$ \\
\hline & $\begin{array}{l}\text { Medical care housing } \\
\left(C_{9}\right)\end{array}$ & $\begin{array}{l}\text { Including medical care space, rehabilitation space } \\
\text { and psychological counseling space }\end{array}$ & $\begin{array}{l}\text { Kane and Kane, 1988; Zhao and } \\
\text { Fang, 2016; Xu and Zhou, 2019; } \\
\text { Wang, 2020; Juan et al., 2021 }\end{array}$ \\
\hline \multirow[t]{2}{*}{ Service } & $\begin{array}{l}\text { Diversity of services } \\
\left(C_{10}\right)\end{array}$ & $\begin{array}{l}\text { Including life care services, catering services, } \\
\text { medical care services, cultural and entertainment } \\
\text { services, rehabilitation services, cleaning services, } \\
\text { washing services, spiritual support services, } \\
\text { hospice services, commissioned services, education } \\
\text { services, and home-based services }\end{array}$ & $\begin{array}{l}\text { Zhao and Fang, 2016; Xu and Zhou, } \\
\text { 2019; Liang and Wang, 2020; Shao } \\
\text { et al., 2020, } 2021\end{array}$ \\
\hline & Service level $\left(C_{11}\right)$ & $\begin{array}{l}\text { The level of quality of various services provided } \\
\text { by the institution, involving the supply capacity } \\
\text { and response speed of service personnel to various } \\
\text { service demands }\end{array}$ & $\begin{array}{l}\text { Xu and Zhou, 2019; Ji et al., 2020; } \\
\text { Wang, 2020; Liang and Wang, 2020; } \\
\text { Shao et al., 2020, } 2021\end{array}$ \\
\hline \multirow[t]{3}{*}{$\begin{array}{l}\text { Operation } \\
\text { management }\end{array}$} & $\begin{array}{l}\text { Service management } \\
\left(C_{12}\right)\end{array}$ & $\begin{array}{l}\text { The management of service personnel and service } \\
\text { items and the construction of service process }\end{array}$ & $\begin{array}{l}\text { Liang and Wang, 2020; Shao et al., } \\
\text { 2020, } 2021\end{array}$ \\
\hline & $\begin{array}{l}\text { Security management } \\
\left(C_{13}\right)\end{array}$ & $\begin{array}{l}\text { The security level of the institution and its } \\
\text { response to the emergencies of the elderly }\end{array}$ & $\begin{array}{l}\text { Kane and Kane, 1988; Liang and } \\
\text { Wang, 2020; Shao et al., 2020, } 2021\end{array}$ \\
\hline & $\begin{array}{l}\text { Personnel management } \\
\left(C_{14}\right)\end{array}$ & $\begin{array}{l}\text { Staff stability, professionalism, quality level and } \\
\text { service attitude }\end{array}$ & $\begin{array}{l}\text { Wang, 2020; Liang and Wang, 2020; } \\
\text { Shao et al., 2020, } 2021\end{array}$ \\
\hline
\end{tabular}


Measure the distances between the performance of the institutions against each criterion and the subjective expectation performance by Eqs (5) and (6). A distance matrix is established as:

$\left[\begin{array}{llllll}0 & 0 & 1000 & 1000 & 1000 & 1000 \\ 1000 & 1000 & 1000 & 1000 & 3000 & 5000 \\ 8000 & 4000 & 500 & 1500 & 3800 & 5970 \\ 20 \% & 5 \% & 10 \% & 15 \% & 20 \% & 40 \% \\ 0.400 & 0.400 & 0.000 & 0.382 & 0.556 & 0.683 \\ 0.359 & 0.516 & 0.556 & 0.701 & 0.821 & 0.872 \\ 0.238 & 0.171 & 0.333 & 0.649 & 0.708 & 0.755 \\ 0.787 & 0.561 & 0.000 & 0.295 & 0.361 & 0.446 \\ 0.600 & 0.000 & 0.403 & 0.375 & 0.499 & 0.719 \\ 0.678 & 0.510 & 0.463 & 0.253 & 0.295 & 0.361 \\ 0.611 & 0.444 & 0.416 & 0.276 & 0.356 & 0.466 \\ 0.572 & 0.425 & 0.425 & 0.347 & 0.221 & 0.263 \\ 0.584 & 0.515 & 0.259 & 0.494 & 0.536 & 0.536 \\ 0.553 & 0.456 & 0.429 & 0.000 & 0.278 & 0.363\end{array}\right]$.

After normalizing these distance values by Eq. (7), the attitudinal weight vector related to alternatives can be deduced as $(0.105,0.213,0.244,0.221,0.139,0.079)^{T}$. The personalized quantifier with cubic spline interpolation associated with the demander can be generated as:

$$
Q(x)=\left\{\begin{array}{c}
2.555 x^{3}+0.559 x, 0 \leq x \leq 0.167 \\
-2.407 x^{3}+2.481 x^{2}+0.506 x-0.037,0.167 \leq x \leq 0.333 \\
-0.320 x^{3}+0.394 x^{2}+1.305 x-0.149,0.333 \leq x \leq 0.5 \\
-1.498 x^{3}+2.161 x^{2}+0.344 x+0.037,0.5 \leq x \leq 0.667 \\
0.647 x^{3}-2.128 x^{2}+2.930 x-0.416,0.667 \leq x \leq 0.833 \\
1.023 x^{3}-3.068 x^{2}+3.514 x-0.467,0.833 \leq x \leq 1
\end{array} .\right.
$$

Based on the generated personalized quantifier and Eq. (4), the position weights of fourteen criteria can be derived as $(0.041,0.046,0.075,0.092,0.099,0.104,0.105$, $0.098,0.093,0.074,0.059,0.048,0.035,0.031$ ).

Subsequently, calculate the average performance of the institutions over each criterion to the reference institution by Eqs ( 8 ) and (9) as:

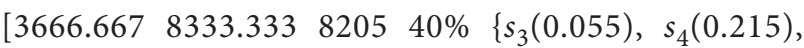
$\left.s_{5}(0.313), s_{6}(0.417)\right\} \quad\left\{s_{1}(0.042), s_{2}(0.139), s_{3}(0.203)\right.$, $\left.s_{4}(0.255), s_{5}(0.194), s_{6}(0.167)\right\}\left\{s_{2}(0.074), s_{3}(0.352)\right.$, $\left.s_{4}(0.107), s_{5}(0.417), s_{6}(0.050)\right\}\left\{s_{2}(0.074)\right.$,

$\left.s_{3}(0.467), s_{4}(0.092), s_{5}(0.200), s_{6}(0.167)\right\}\left\{s_{1}(0.050)\right.$, $\left.s_{2}(0.050), s_{3}(0.109), s_{4}(0.158), s_{5}(0.354), s_{6}(0.279)\right\}$

$\left\{s_{3}(0.292), s_{4}(0.304), s_{5}(0.321), s_{6}(0.083)\right\}\left\{s_{3}(0.292)\right.$, $\left.s_{4}(0.297), s_{5}(0.291), s_{6}(0.120)\right\}\left\{s_{4}(0.287), s_{5}(0.630)\right.$,

$\left.\mathrm{s}_{6}(0.083)\right\} \quad\left\{s_{3}(0.458), s_{4}(0.097), s_{5}(0.278), s_{6}(0.167)\right\}$ $\left.\left\{s_{4}(0.173), s_{5}(0.398), s_{6}(0.429)\right\}\right]^{T}$.

Compare the performances of institutions with that of the reference institution under each criterion, and measure the distances between the institutions and the reference institution. The positive distance matrix and negative distance matrix are formed as:

$\left[\begin{array}{llllll}0 & 0 & 0.500 & 0 & 0 & 0.500 \\ 0 & 0.438 & 0.438 & 0.063 & 0 & 0.063 \\ 0 & 0.319 & 0.656 & 0 & 0.025 & 0 \\ 0 & 0.667 & 0.333 & 0 & 0 & 0 \\ 0 & 0.247 & 0 & 0.376 & 0.376 & 0 \\ 0.262 & 0.423 & 0.238 & 0 & 0 & 0.077 \\ 0 & 0.329 & 0.376 & 0 & 0.295 & 0 \\ 0 & 0 & 0.413 & 0 & 0.587 & 0 \\ 0.339 & 0 & 0.257 & 0 & 0.245 & 0.159 \\ 0.248 & 0 & 0.298 & 0 & 0.454 & 0 \\ 0.428 & 0 & 0.297 & 0.275 & 0 & 0 \\ 0 & 0.256 & 0 & 0 & 0.256 & 0.488 \\ 0.406 & 0.228 & 0.366 & 0 & 0 & 0 \\ 0.407 & 0.282 & 0 & 0.310 & 0 & 0\end{array}\right]$,
$\left[\begin{array}{llllll}0.250 & 0.250 & 0 & 0.250 & 0.250 & 0 \\ 0.688 & 0 & 0 & 0 & 0.313 & 0 \\ 0.520 & 0 & 0 & 0.337 & 0 & 0.143 \\ 0 & 0 & 0 & 0.222 & 0.667 & 0.111 \\ 0.133 & 0 & 0.499 & 0 & 0 & 0.368 \\ 0 & 0 & 0 & 0.553 & 0.447 & 0 \\ 0.409 & 0 & 0 & 0.344 & 0 & 0.248 \\ 0.298 & 0.249 & 0 & 0.092 & 0 & 0.361 \\ 0 & 0.626 & 0 & 0.374 & 0 & 0 \\ 0 & 0.428 & 0 & 0.185 & 0 & 0.387 \\ 0 & 0.325 & 0 & 0 & 0.269 & 0.407 \\ 0.089 & 0 & 0.560 & 0.351 & 0 & 0 \\ 0 & 0 & 0 & 0.345 & 0.310 & 0.345 \\ 0 & 0 & 0.408 & 0 & 0.349 & 0.243\end{array}\right]$.

Arrange each column of the positive distance matrix in descending order, and arrange each column of the negative distance matrix in ascending order. Based on the derived position weights of criteria and Eqs (10) and (11), the distance values of each institution which are superior or inferior to the reference institution are aggregated to obtain two subordinate comprehensive scores of each institution. Next, integrate the two subordinate comprehensive scores to gain the final comprehensive score of each institution. For the sake of generality, the values of the two coordination parameters $\lambda$ and $\mu$ are both set as 0.5 . The results of these calculations are displayed in Table 2. On the basis of the final comprehensive scores, the ranking of these institutions is $\mathrm{PI}_{3} \succ \mathrm{PI}_{2} \succ P I_{5} \succ P I_{1} \succ \mathrm{PI}_{6} \succ P I_{4}$, and the most suitable pension service institution is $\mathrm{PI}_{3}$.

Table 2. The comprehensive scores and ranks of the institutions

\begin{tabular}{|l|c|c|c|c|}
\hline & $C S_{i}^{1}$ & $C S_{i}^{2}$ & $C S_{i}$ & Ranks \\
\hline$P I_{1}$ & 0.088 & -0.002 & -0.076 & 4 \\
\hline$P I_{2}$ & 0.445 & 0.004 & 0.409 & 2 \\
\hline
\end{tabular}


End of Table 2

\begin{tabular}{|l|l|l|l|l|}
\hline & \multicolumn{1}{|c|}{$C S_{i}^{1}$} & \multicolumn{1}{c|}{$C S_{i}^{2}$} & \multicolumn{1}{c|}{$C S_{i}$} & \multicolumn{1}{c|}{ Ranks } \\
\hline$P I_{3}$ & 0.758 & 0.003 & 0.550 & 1 \\
\hline$P I_{4}$ & -0.386 & -0.008 & -0.595 & 6 \\
\hline$P I_{5}$ & 0.024 & 0.000 & -0.003 & 3 \\
\hline$P I_{6}$ & -0.263 & -0.002 & -0.228 & 5 \\
\hline
\end{tabular}

\section{Sensitive analysis and comparative analysis}

Based on the data in the case study, we further explore the influence of the changes of two coordination parameters in the proposed MCDM method on the decision results. Moreover, the effectiveness of the proposed personalized quantifier-based MACONT method is verified by comparing it with the original MACONT method (Wen et al., 2020) and the EDAS (evaluation based on distance from average solution) method (Keshavarz Ghorabaee et al., 2015; Turskis et al., 2017).

\subsection{Sensitive analysis}

The values of the coordination parameters $\lambda$ and $\mu$ in the two aggregation operators (Eqs (10) and (11)) are identified according to the preference of the decision-maker. In Section 3, both coordination parameters are taken as 0.5 . Different values of these two parameters would result in different scores, and thus may produce different ranking results. In this section, we take the two parameters as any one of the value set $\{0,0.1,0.2,0.3,0.4,0.5,0.6,0.7,0.8$, $0.9,1\}$. The final comprehensive scores of institutions are shown in Figure 2.

From Figure 2, we can find that, under the condition of two parameter values changing, the final comprehensive score of each institution has change, but the ranking of these institutions does not change. When $\lambda=0$ and $\mu=1$, the final comprehensive scores of these institutions are $(0.174,0.321,0.371,0.082,0.223,0.146)$, and the corresponding ranking is $P I_{3} \succ P I_{2} \succ P I_{5} \succ P I_{1} \succ P I_{6} \succ P I_{4}$.

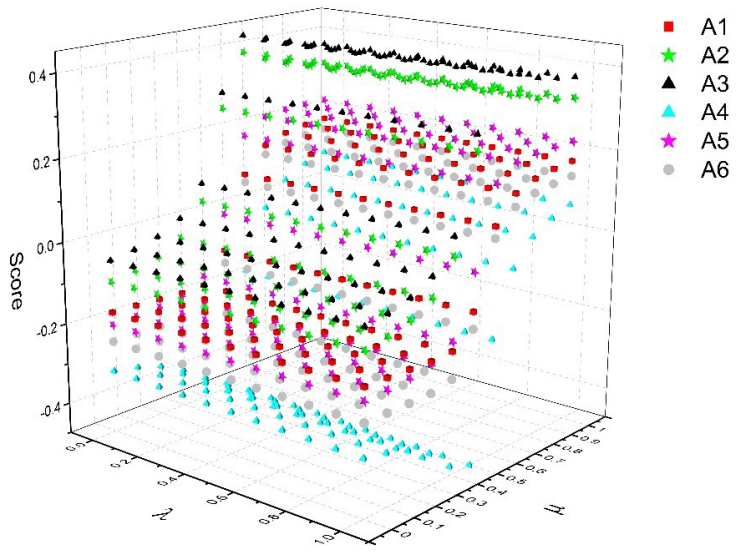

Figure 2. The final comprehensive score of each institution under the condition of two parameter values changing
When $\lambda=1$ and $\mu=0$, the final comprehensive scores of these institutions are $(-0.173,-0.093,-0.041,-0.335$, $-0.205,-0.254)$, and the corresponding ranking is $P I_{3} \succ P I_{2} \succ P I_{1} \succ P I_{5} \succ P I_{6} \succ P I_{4}$. It is obvious that the change of the values of the two parameters makes the score of each institution change, and makes the ranks of the institutions $P I_{1}$ and $P I_{5}$ change. This reflects that the improved MACONT method can mobilize the subjective initiative of the decision-maker, such that the decisionmaking results may change with the preference value given by the decision-maker according to specific situation, which highlights the flexibility of the improved MACONT method in practical applications.

\subsection{Comparative analysis}

\subsubsection{Comparison with the original MACONT method}

In the original MACONT method (Wen et al., 2020), the individual performances of alternatives are calculated by $\prod_{j=1}^{n}\left(H_{i j}^{-}\right)^{w_{j}} / \prod_{j=1}^{n}\left(H_{i j}^{+}\right)^{w_{j}}$. According to this operator, we can get the individual performance of each institution as $(0.856,1.810,2.292,0.550,1.500,0.781)$. From the negative distance matrix obtained from the case study, we can see that the number of negative distance values between institutions $P I_{1}, P I_{5}$ and the reference institution is the same, but most of the negative distance values of the institution $P I_{1}$ are less than that of the institution $P I_{5}$. That is to say, the individual performance of the institution $P I_{1}$ should be better than that of the institution $P I_{5}$. However, the individual performance of the institution $P I_{1}$ calculated by the original MACONT method is worse than that of the institution $P I_{5}(0.856<1.500)$, which is unreasonable.

In contrast, the individual performance of each institution calculated by the improved MACONT method is $(0.028,0.145,0.251,-0.118,0.008,-0.082)$. The individual performance of the institution $P I_{1}$ is better than that of the institution $P I_{5}(0.028>0.008)$, which improves the rationality of the aggregation results.

\subsubsection{Comparison with the EDAS method}

Since both the EDAS (Keshavarz Ghorabaee et al., 2015; Turskis et al., 2017) method and MACONT method derive the final alternative ranking based on the positive and negative distances between the performances of alternatives and the average performance, we combine the personalized quantifier $Q(x)$ with the EDAS method to verify the rationality of the proposed model.

The expectation value function $E\left(L_{i j}(p)\right)=$ $\sum_{t=1}^{T} \frac{\alpha^{(t)}}{2 \tau} p_{1}^{*(t)}(\mathrm{Wu} \&$ Liao, 2019) is used here to convert the PLTSs of the average performances of institutions into crisp values. Based on the quotient of each element in the positive and negative distance matrices and the average performance values of the institutions under each criterion, the positive and negative distances from the average performance values of the institutions can be gained. 
Table 3. The calculation results and ranking of institutions derived by the EDAS method

\begin{tabular}{|c|c|c|c|c|c|c|}
\hline & $P S_{i}$ & $N S_{i}$ & $N P S_{i}$ & $N N S_{i}$ & $A S_{i}$ & Ranks \\
\hline$P I_{1}$ & 0.313 & 0.133 & 0.581 & 0.489 & 0.535 & 3 \\
\hline$P I_{2}$ & 0.373 & 0.113 & 0.693 & 0.565 & 0.629 & 2 \\
\hline$P I_{3}$ & 0.539 & 0.066 & 1.000 & 0.748 & 0.874 & 1 \\
\hline$P I_{4}$ & 0.085 & 0.259 & 0.158 & 0.007 & 0.083 & 5 \\
\hline$P I_{5}$ & 0.297 & 0.162 & 0.551 & 0.378 & 0.464 & 4 \\
\hline$P I_{6}$ & 0.080 & 0.261 & 0.148 & 0.000 & 0.074 & 6 \\
\hline
\end{tabular}

Then, combined with the position weights of criteria deduced by the personalized quantifier $Q(x)$, the distances of each institution in the two matrices are respectively integrated by the OWA operator. The positive and negative aggregation scores, represented as $P S_{i}$ and $N S_{i}$, are then normalized by $P S_{i} / \max P S_{i}$ and $1-N S_{i} / \max N S_{i}$, respectively. The appraisal scores of the institutions, $A S_{i}$, can be determined by the average value between the two normalized aggregation scores. The calculation and ranking results are shown in Table 3.

From Table 3, we can find that the optimal pension service institution determined by the EDAS method is also $\mathrm{PI}_{3}$, but the rankings of those institutions obtained by the EDAS and the improved MACONT methods are different. Both methods set up an average solution as a reference, but these two methods are different in specific operations. The MACONT method is based on the distances between the performances of institutions and the average performances of institutions, and the form of performances is not necessarily crisp values. By contrast, the EDAS method is based on the quotient of distances and average performance values, and thus it needs to transform the average performances of institutions into crisp values, resulting in possible information loss. In addition, the EDAS method only uses a single aggregation operator to aggregate the distances between the performances of institutions and the average performances of institutions, while the improved MACONT method uses multiple aggregation operators. In this sense, the improved MACONT method makes the final result more comprehensive and reliable than that of the EDAS method.

The above sensitivity analysis and comparative analysis illustrate the flexibility and reliability of the improved MACONT method. It also implies that the personalized quantifiers can be used as a method to derive the position weights of criteria, and combined with the MCDM methods to determine the ranking of institutions associated with the attitude of pension service demanders.

\section{Conclusions}

This study mainly presented a personalized quantifierbased MACONT method to solve the MCDM problem of selecting pension service institutions. In the determination of evaluation criteria of pension service institutions, key evaluation criteria were identified based on the analy- sis of the relevant literature, which provides reference for the pension service demanders in selecting the pension service institutions. Furthermore, the identified evaluation criteria not only provide reference for the factors that real estate enterprises need to pay attention to in the investment and construction of pension service construction projects, but also provide reference for the relevant property enterprises to consider which key factors to improve the quality of pension service and improve the level of property management. In the proposed personalized quantifier-based MACONT method, crisp values and PLTSs were adopted to respectively express the evaluation information of quantitative and qualitative criteria. The improved MACONT method was combined with personalized quantifiers determined by cubic spline interpolation. To verify the feasibility of the proposed model, we provided a case study on the evaluation and selection of pension service institutions. The advantages of the proposed method were emphasized by sensitivity analysis and comparative analysis. The proposed method was verified to be effective and reliable in dealing with heterogeneous evaluation information. The improved MACONT method is flexible and reliable, and the personalized quantifiers can be combined with MCDM methods to obtain an optimal solution associated with the attitude of decision-makers. Pension service demanders can add or delete evaluation criteria from the set of criteria given in the case study according to their own needs.

Actually, qualitative and quantitative evaluation information can also be diversified, such as interval values, interval-valued intuitionistic fuzzy values (Gorzalczany, 1987), and grey numbers (Li et al., 2007). The proposed model only adopted crisp values and PLTSs as representations to respectively express qualitative and quantitative evaluation information. It provided ideas for the processing of diversified information expression forms. In the future, we will study the processing of diversified evaluation information and further explore the applications of personalized quantifiers. Additionally, due to the sharp increase of the elderly population, the mismatch between the existing facilities and the demand for the elderly leads to insufficient supply, as well as the strong support of the government, the real estate for the elderly has become a hot topic. It is a research direction to further improve and apply the proposed method to the risk assessment and selection of pension real estate projects. 


\section{Funding}

This work was supported by the National Natural Science Foundation of China under Grant 71771156, Grant 71971145, Grant 72171158, and the Chengdu Planning Project of Social Science under Grant 2019L09.

\section{Author contributions}

Authors contributed equally to this work.

\section{Disclosure statement}

The authors have no competing financial, professional, or personal interests from other parties that are related to this paper.

\section{References}

Bai, C. Z., Zhang, R., Qian, L. X., \& Wu, Y. N. (2017). Comparisons of probabilistic linguistic term sets for multi-criteria decision making. Knowledge-Based Systems, 119, 284-291. https://doi.org/10.1016/j.knosys.2016.12.020

Brauers, W. K. M., \& Zavadskas, E. K. (2010). Project management by MULTIMOORA as an instrument for transition economies. Technological and Economic Development of Economy, 16(1), 5-24. https://doi.org/10.3846/tede.2010.01

Gorzalczany, M. B. (1987). A method of inference in approximate reasoning based on interval-valued fuzzy sets. Fuzzy Sets Systems, 21(1), 1-17. https://doi.org/10.1016/0165-0114(87)90148-5

Guo, K. H. (2014). Quantifier induced by subjective expected value of sample information. IEEE Transactions on Cybernetics, 44(10), 1784-1794. https://doi.org/10.1109/TCYB.2013.2295316

Guo, K. H. (2016). Quantifier induced by subjective expected value of sample information with Bernstein polynomials. European Journal of Operational Research, 254, 226-235. https://doi.org/10.1016/j.ejor.2016.03.015

Guo, K. H., \& Xu, H. (2018). Personalized quantifier by Bernstein polynomials combined with interpolation spline. International Journal of Intelligent Systems, 33, 1507-1533. https://doi.org/10.1002/int.21991

Ji, L., Fan, W. F., \& Liu, H. G. (2020). Research on performance evaluation of government purchase of pension services from social forces based on the investigation in the Yangtze River delta. Yuejiang Academic Journal, 4, 79-123.

https://doi.org/10.13878/j.cnki.yjxk.2020.04.009

Juan, Y. K., Hsus, Y. C., \& Chang, Y. P. (2021). Site selection assessment of vacant campus space transforming into daily care centers for the aged. International Journal of Strategic Property Management, 25(1), 34-49. https://doi.org/10.3846/ijspm.2020.13800

Kane, A. R., \& Kane, L. R. (1988). Long-term care: variations on a quality assurance theme. Inquiry, 25(1), 132-146.

Keshavarz Ghorabaee, M., Zavadskas, E. K., Olfat, L., \& Turskis, Z. (2015). Multi-criteria inventory classification using a new method of evaluation based on distance from average solution (EDAS). Informatica, 26, 435-451. https://doi.org/10.15388/Informatica.2015.57

Liang, J. J., \& Wang, Y. M. (2020). Study on the performance evaluation of community home endowment service institu- tions: a case study of Shanghai. Engineering Economy, 30(1), 74-77. https://doi.org/10.19298/j.cnki.1672-2442.202001074

Li, G. D., Yamaguchi, D., \& Nagai, M. (2007). A grey-based decision-making approach to the supplier selection problem. Mathematical and Computer Modelling, 46(3-4), 573-581. https://doi.org/10.1016/j.mcm.2006.11.021

Lin, M. W., Chen, Z. Y., Liao, H. C., \& Xu, Z. S. (2019). ELECTRE II method to deal with probabilistic linguistic term sets and its application to edge computing. Nonlinear Dynamics, 96, 2125-2143. https://doi.org/10.1007/s11071-019-04910-0

Liao, H. C., Mi, X. M., \& Xu, Z. S. (2020). A survey of decisionmaking methods with probabilistic linguistic information: bibliometrics, preliminaries, methodologies, applications and future directions. Fuzzy Optimization Decision Making, 19, 81-134. https://doi.org/10.1007/s10700-019-09309-5

Liao, H. C., Xu, Z. S., Zeng, X. J., \& Merigó, J. M. (2015). Qualitative decision making with correlation coefficients of hesitant fuzzy linguistic term sets. Knowledge-Based Systems, 76, 127-138. https://doi.org/10.1016/j.knosys.2014.12.009

Mi, X. M., Liao, H. C., Wu, X. L., \& Xu, Z. S. (2020). Probabilistic linguistic information fusion: a survey on aggregation operators in terms of principles, definitions, classifications, applications, and challenges. International Journal of Intelligent Systems, 35(3), 529-556. https://doi.org/10.1002/int.22216

Pang, Q., Wang, H., \& Xu, Z. S. (2016). Probabilistic linguistic term sets in multi-attribute group decision making. Information Science, 369, 128-143.

https://doi.org/10.1016/j.ins.2016.06.021

Rodríguez, R. M., Martinez, L., \& Herrera, F. (2012). Hesitant fuzzy linguistic term sets for decision making. IEEE Transactions on Fuzzy Systems, 20(1), 109-119.

https://doi.org/10.1109/TFUZZ.2011.2170076

Shao, Q. H., Yuan, J. F., Lin, J., Huang, W., Ma, J. W., \& Ding, H. X. (2021). An SBM-DEA based performance evaluation and optimization for social organizations participating in community and home-based elderly care services. PLOS ONE, 16(3), 1-25. https://doi.org/10.1371/journal.pone.0248474

Shao, Q. H., Yuan, J. F., Zheng, C. L., \& Lin, J. (2020). Performance evaluation of social organizations participating in home care services. China Real Estate, 58-66. https://doi.org/10.13562/j.china.real.estate.2020.02.016

Turskis, Z., Morkunaite, Z., \& Kutut, V. (2017). A hybrid multiple criteria evaluation method of ranking of cultural heritage structures for renovation projects. International Journal of Strategic Property Management, 21(3), 318-329. https://doi.org/10.3846/1648715X.2017.1325782

Wang, K. (2020). Quality of home-based service: concept, assessment and policy response. Social Policy Research, 89-102. https://doi.org/10.19506/j.cnki.cn10-1428/d.2020.03.009

Wen, Z., Liao, H. C., \& Emrouznejad, A. (2021). Information representation of blockchain technology: risk evaluation of investment by personalized quantifier with cubic spline interpolation. Information Processing \& Management, 58(4), 102571. https://doi.org/10.1016/j.ipm.2021.102571

Wen, Z., Liao, H. C., \& Zavadskas, E. K. (2020). MACONT: mixed aggregation by comprehensive normalization technique for multi-criteria analysis. Informatica, 31(4), 857-880. https://doi.org/10.15388/20-INFOR417

Wu, X. L., \& Liao, H. C. (2018). An approach to quality function deployment based on probabilistic linguistic term sets and ORESTE method for multi-expert multi-criteria decision making. Information Fusion, 43, 13-26. https://doi.org/10.1016/j.inffus.2017.11.008 
Wu, X. L., \& Liao, H. C. (2019). A consensus-based probabilistic linguistic gained and lost dominance score method. European Journal of Operational Research, 272, 1017-1027. https://doi.org/10.1016/j.ejor.2018.07.044

Xu, Q., \& Zhou, Y. (2019). Performance evaluation and influencing factors analysis of community home care service quality. Journal of Guangdong Institute of Public Administration, 31(5), 77-86. https://doi.org/10.13975/j.cnki.gdxz.2019.05.010

Yager, R. R. (1988). On ordered weighted averaging aggregation operators in multi-criteria decision making. IEEE Transactions on Systems, Man, and Cybernetics, 18(1), 183-190. https://doi.org/10.1109/21.87068

Yuan, J., Li, L., Wang, E., \& Skibniewski, M. J. (2019). Examining sustainability indicators of space management in elderly facilities - a case study in China. Journal of Cleaner Production, 208, 144-159. https://doi.org/10.1016/j.jclepro.2018.10.065
Zavadskas, E. K., Turskis, Z., Antucheviciene, J., \& Zakarevicius, A. (2012). Optimization of weighted aggregated sum product assessment. Electronics and Electrical Engineering, 122(6), 3-6. https://doi.org/10.5755/j01.eee.122.6.1810

Zhang, Y. X., Xu, Z. S., Wang, H., \& Liao, H. C. (2016). Consistency-based risk assessment with probabilistic linguistic preference relation. Applied Soft Computing, 49, 817-833. https://doi.org/10.1016/j.asoc.2016.08.045

Zhao, N., \& Fang, W. H. (2016, August 18-20). Research on the service quality evaluation model of institutional pension a case study of Beijing city. In International Conference on Management Science and Engineering - Annual Conference Proceedings (pp. 802-809), Olten, Switzerland. 